\title{
DEVELOPMENT OF A VALIDATED MODEL FOR USE IN MINIMIZING NOx EMISSIONS AND MAXIMIZING CARBON UTILIZATION WHEN COFIRING BIOMASS WITH COAL
}

\author{
Quarterly Report
}

Reporting Period Start Date: 10/1/2000

Reporting Period End Date: 12/31/2000

\author{
Larry G. Felix, SRI \\ P. Vann Bush, SRI \\ Stephen Niksa, NEA
}

January 24, 2001

DOE Cooperative Agreement No. DE-FC26-00NT40895

Southern Research Institute
2000 Ninth Avenue South
P. O. Box 55305
Birmingham, AL 35255-5305

Niksa Energy Associates

1745 Terrace Drive

Belmont, CA 94002 


\section{DISCLAIMER}

"This report was prepared as an account of work sponsored by an agency of the United States Government. Neither the United States Government nor any agency thereof, nor any of their employees, makes any warranty, express or implied, or assumes any legal liability or responsibility for the accuracy, completeness, or usefulness of any information, apparatus, product, or process disclosed, or represents that its use would not infringe privately owned rights. Reference herein to any specific commercial product, process, or service by trade name, trademark, manufacturer, or otherwise does not necessarily constitute or imply its endorsement, recommendation, or favoring by the United States Government or any agency thereof. The views and opinions of authors expressed herein do not necessarily state or reflect those of the United States Government or any agency thereof." 


\begin{abstract}
This is the first Quarterly Technical Report for DOE Cooperative Agreement No. DE-FC26-00NT40895. A statement of the project objectives is included in the Introduction of this report. The project goals and detailed plans were presented in two project kickoff meetings; one at NETL in Pittsburgh and one in Birmingham, AL at Southern Research Institute. Progress has been made in developing a modeling approach to synthesize the reaction time and temperature distributions that will be produced by computational fluid dynamic models of the pilot-scale combustion furnace and the char burnout and chemical reaction kinetics that will predict NOx emissions and unburned carbon levels in the furnace exhaust. Preparations are under way for the initial pilot-scale combustion experiments.
\end{abstract}




\section{TABLE OF CONTENTS}

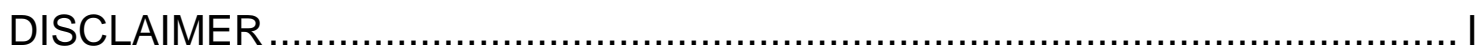

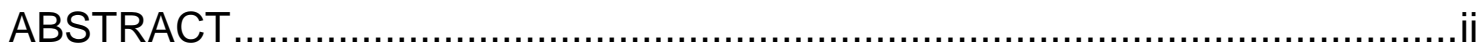

TABLE OF CONTENTS ......................................................................

INTRODUCTION

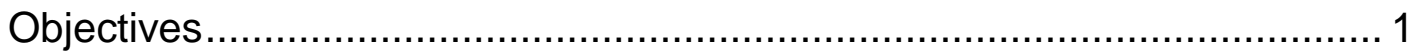

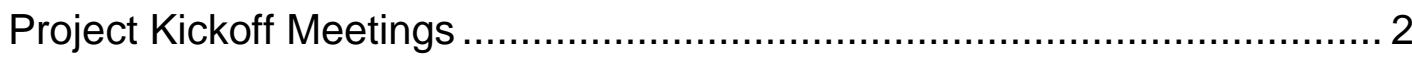

EXPERIMENTAL

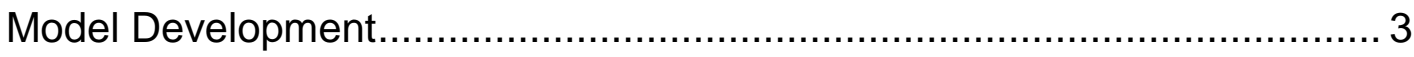

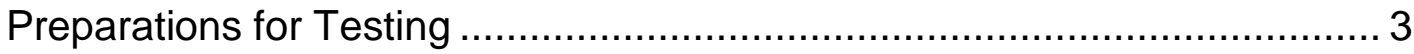

Size Reduction of Biomass......................................................................... 4

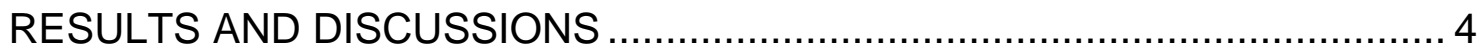

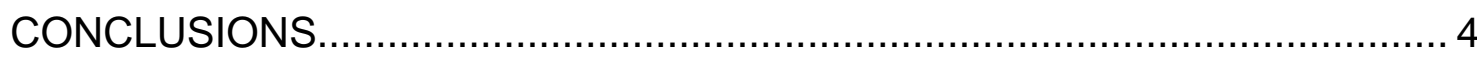

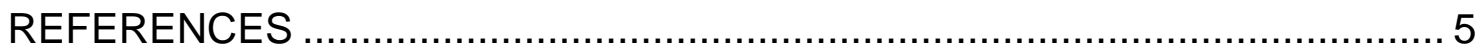

Appendix. Translating CFD Simulations into Equivalent Reactor Networks....... 6 


\section{INTRODUCTION}

The work to be conducted in this project received funding from the Department of Energy under Cooperative Agreement No. DE-FC26-00NT40895. This project has a period of performance that commenced September 20, 2000 and continues through September 19, 2002. A project Work Plan was submitted to DOE on October 18, 2000 as the first deliverable under the cooperative agreement. The Work Plan is not included in this report, but the objectives of the project are restated from the Work Plan in the following paragraphs.

\section{Objectives}

The project is designed to balance the development of a systematic and expansive database detailing the effects of cofiring parameters on NOx formation with the complementary modeling effort that will yield a capability to predict, and therefore optimize, NOx reductions by the selection of those parameters.

The database of biomass cofiring results will be developed through an extensive set of pilot-scale tests at the Southern Company/Southern Research Institute Combustion Research Facility. The testing in this program will monitor NOx, LOI, and other emissions over a broad domain of biomass composition, coal quality, and cofiring injection configurations to quantify the dependence of NOx formation and LOI on these parameters. This database of cofiring cases will characterize an extensive suite of emissions and combustion properties for each of the combinations of fuel and injection configuration tested.

The complementary process modeling will expand the value of the raw test data by identifying the determining factors on NOx emissions and LOI. Niksa Energy Associates will develop and validate a detailed process model for predicting NOx emissions and LOI from biomass cofiring that builds on a foundation of existing and proven fluid dynamics, reaction kinetics, and combustion products models. The modeling will resolve all major independent influences, including biomass composition, coal quality, chemical interactions among biomass-and coal-derived intermediate species, competitive $\mathrm{O}_{2}$ consumption by biomass- and coal-derived intermediate species and chars, extent of biomass/coal mixing prior to combustion, and mixing intensity during biomass injection.

The overall goal of the project is to produce a validated tool or methodology to accurately and confidently design and optimize biomass cofiring systems for fullscale utility boilers to produce the lowest $\mathrm{NO}_{\mathrm{x}}$ emissions and the least unburned carbon. Specific program objectives are: 
- Develop an extensive data set under controlled test conditions that quantifies the relationships between $\mathrm{NO}_{x}$ emissions and biomass cofiring parameters.

- Provide a data set of the effects of biomass cofiring over a broad range of fuels and cofiring conditions on flame stability, carbon burnout, slagging and fouling, and particulate and gaseous emissions.

- Develop and validate a broadly applicable computer model that can be used to optimize $\mathrm{NO}_{x}$ reductions and minimize unburned carbon from biomass cofiring.

Once validated, the model provides a relatively inexpensive means to either (1) identify the most effective cofiring injection configuration for specified compositions of biomass and coal within a particular furnace environment, or (2) to forecast the emissions for a specified pair of fuels fired under an existing configuration. As such an important cost-saving tool, the modeling has the potential to accelerate widespread adoption of biomass cofiring as a $\mathrm{NO}_{x}$ control strategy in the electric utility industry.

\section{Project Kickoff Meetings}

On October 24, 2000 Southern Research Institute (SRI) and Southern Company Services (SCS) participated in a project kick-off meeting at the National Energy Technology Center in Pittsburgh, PA, where a summary of the project was presented by Vann Bush. (The presentation materials are available from the author.)

On November 15, 2000 a project kickoff meeting was held at the SRI laboratories in Birmingham, AL. Attending in addition to the SRI project team were Dr. Steve Niksa of Niksa Energy Associates (NEA), Dr. Kevin Davis of Reaction Engineering International (REI), and Drs. Doug Boylan and Larry Monroe of SCS. Project schedule, computational fluid dynamic (CFD) models of the pilot-scale furnace, test design, model validations, and project deliverables were discussed.

REI requested specific sets of design and operating parameters for the SRI/SCS Pilot-Scale Combustion Research Facility. In addition to the information conveyed at the meeting, a data package is in preparation to supply REI the information required to build the CFD models required in this project. 


\section{EXPERIMENTAL}

\section{Model Development}

As a result of discussions at the project kickoff meeting, Niksa Energy Associates prepared a document with the title "Translating CFD Simulations into Equivalent Reactor Networks." The document includes summary descriptions of various approaches that could be used to develop the building blocks of a model that collectively define the evolution of $\mathrm{NO}_{x}$ emissions and the burnout of char from the combustion of biomass and coal mixtures. CFD simulations provide the framework for the models, primarily in the form of time and temperature distributions, but there are several approaches to defining the scale of specific regions of the simulation that represent individual reaction regimes.

A series or network of equivalent reactors has to be developed to simulate the complete reaction time-temperature history for each furnace and fuel-mixing configuration. These may be a combination of plug-flow and stirred-tank reactors. The approach being developed by NEA is to use a threshold in the calculated carbon fraction as the boundary that defines the domain of a particular reactor. This approach is evaluated in the context of other possible approaches in an Appendix to this report.

\section{Preparations for Testing}

The combustor is being readied for biomass cofiring tests. We expect to carry out our first run with switchgrass and dry hardwood sawdust as primary biomass fuels in late January or early February. Poultry litter was originally scheduled for our first round of tests. However, tests with that fuel have been delayed until a proper dry covered storage area is constructed (construction of such an area is imminent). Sawdust was selected as a substitute for poultry litter because it also represents an extreme case among our selection of fuels in terms of fuel nitrogen content. Whereas switchgrass has a nominal $1 \%$ fuel nitrogen content, we expect the sawdust to have between 0.1 and $0.3 \%$ fuel nitrogen content.

A source of kiln-dried, hardwood sawdust was located in Tuscaloosa, AL. This sawdust is from a stair-tread manufacturing company consisting of typically over $90 \%$ oak and no softwood. The moisture content is nominally $6-8 \%$. Complete analyses of the as-received fuels will be conducted after the material is delivered in January 2001. 


\section{Size Reduction of Biomass}

SRI has been contacted by Mesa Reduction Engineering and Processing, Inc., a company that produces a unique collision mill that can be used to reduce biomass to an almost powder-like state. Size of the biomass was added as a test variable during contract negotiations since it is anticipated to affect the burnout and reaction rates during combustion. We are discussing the possibility of collaborating with Mesa so that we can generate and test a consistently sized biomass product during each of the upcoming pilot-scale tests. A portable version of the Mesa collision mill may be available for the preparation of finely divided biomass for co-milling with coal and for direct furnace injection.

\section{RESULTS AND DISCUSSION}

SRI has provided to REI the information necessary for the production of CFD models of the combustion research facility. Several cases will be simulated to include two coal burner configurations and four cofiring configurations. These simulations are prerequisite to the NOx and carbon burnout modeling.

There has been progress in the development of a strategy for the construction of the process model that will yield predictions of NOx emission rates and carbon burnout efficiency. NEA has conceived an innovative approach for specifying a system of reactors based on the integrated carbon fraction over reaction zones in the furnace. This approach is being developed to help determine the system of reactors in which the CBK, Chemkin III ${ }^{\circledR}$ and bio-Flashchain ${ }^{\circledR}$ modules are used in the PC Coal Lab ${ }^{\circledR}$ calculations of NOx and unburned carbon.

Initial pilot-scale tests will investigate sawdust and switchgrass, each mixed at two concentrations with a bituminous coal. We will begin tests with the co-milled coal and biomass. Since test results will provide the experimental data to validate the modeling approach, it is advantageous for the initial tests to be a simple cofiring case. Co-milling and co-injection of the intimately mixed fuels is the simplest fuel mixing configuration, and the one we think we understand the best.

\section{CONCLUSIONS}

Important progress has been made in getting this project started. In particular, the modeling effort has already yielded an innovative approach toward defining 
reaction zones in a combustion system. This development is a generally applicable algorithm that, if proven successful, should benefit other process modeling efforts in which carbon consumption or conversion is a major component.

Expenditures have been less than projected. Subcontracting delays are partly responsible for lower billings than planned from REI and NEA. REI expects that the CFD modeling effort will experience more intense activity in the first quarter of CY 2001. Also, because of other work at the SRI/SCS Pilot-Scale Combustor, not as many hours were expended by SRI as were scheduled for planning and preparation. However, during the first quarter of 2001 intensive project activity is expected.

Plans for the next quarter include completion of a CFD simulation by REI, Inc., incorporation of bio-Flashchain ${ }^{\circledR}$ into PC Coal Lab ${ }^{\circledR}$, acquisition of dry hardwood sawdust from a local supplier, and the first combustor runs with sawdust and switchgrass. In the first combustor run, sawdust and switchgrass will be first comilled with coal at target levels of $10 \%$ and $20 \%$ (mass basis) and in the second combustor run, both biomass materials will be directly injected through the center of the single register burner.

\section{REFERENCES}

L. S. Pedersen, P. Glarborg, K. Dam-Johansen, P. W. Hepburn, and G. Hesselmann, "A chemical engineering model for predicting NO emissions and burnout from pulverized coal flames," Combust. Sci. and Tech., 132: 251-314 (1998).

D. Benedetto, S. Pasini, M. Falcitelli, C. LaMarca, and L. Tognotti, "NOx emission prediction from 3-D complete modeling to reactor network analysis," Combust. Sci. and Tech., 153: 279-294 (2000).

W. A. Fiveland, C. E. Latham, A. D. LaRue, "Combustion system optimization by advanced modeling technology," In Combustion Modeling and Burner Replacement Strategies, Vol. 10, R. V. Nayak and N. A. Mousa (Eds.), FACT Div., ASME, 1990 Int. Joint Power Generation Conf., Oct. 21-25, 1990, Boston, MA, ASME, 1990, NY, NY, pp. 15-22. 


\title{
APPENDIX
}

\section{TRANSLATING CFD SIMULATIONS INTO EQUIVALENT REACTOR NETWORKS}

\author{
Stephen Niksa, Niksa Energy Associates, Belmont, CA \\ November 17, 2000
}

CNEA, 2000

\subsection{INTRODUCTION}

During our recent kickoff meeting at SRI, we discussed NEA's modeling approach whereby detailed reaction mechanisms are implemented in a network of idealized chemical reactors. The reactor network should be "equivalent" to the CFD flow and temperature fields, in the sense that it imposes the same residence time distribution (RTD) and mixing intensities on the flow. In fact, specifications on equivalent reactor networks are currently being developed by several European research groups, and there is no consensus procedure; the specification has not yet been reduced to an analytical formalism, although that is the ultimate goal.

At the meeting, I talked at length about the approach taken by Glarborg and coworkers, but mentioned the others only in passing to focus the introduction of this topic for the rest of the team. Now that we have all seen the basic approach, it is worth considering two alternative approaches. I think there are major limitations to all three approaches, primarily because each one is conceptually well suited for some, but not all, of the essential aspects of $\mathrm{NO}_{\mathrm{X}}$ and $\mathrm{CO}$ production and carbon burnout. These limitations are especially important with regard to the prospects for scaling up our methodology to much more complex furnace environments. My summary suggestion is a novel approach that will be described after the survey of previous approaches. If possible, we should implement as many approaches as possible in this test program, so that we have a better basis to select the best method for follow-on work.

\subsection{BACKGROUND}

The primary reference for each approach is cited in the subsections to follow. Please let me know if you want hard copies of any of them.

\subsection{Zoning with Distributed Mixing (ZwDM)}

This method is the one implemented by Glarborg and coworkers, and discussed at length in the meeting. The definition of the equivalent network proceeds through the following seven steps: 
(1) Classify flame type.

(2) Determine RTDs from the CFD simulations with particle tracking.

(3) Subdivide into zones.

(4) Assign reactor types for each zone.

(5) Determine the RTD for the equivalent network and match to the CFD-based RTD.

(6) Specify macromixing parameters.

(7) Simulate the chemistry.

The main advantage of this approach is that is has already been applied to furnaces like SRI's over a wide size range from $160 \mathrm{~kW}$ to $12 \mathrm{MW}$. That is, we could immediately specify networks from the literature for coal-only, coal/biomass blends, and coaxial biomass co-firing configurations, and have a plausible candidate network for on- and offaxis co-firing. The main disadvantage is step 6 , in which the time constants for mixing are tuned-in to match the predicted emissions for selected baseline cases, then left alone for other evaluations. This approach is a poor substitute for using the field of S. R. from the CFD solutions to directly indicate the extent of mixing among all streams in the nearburner zone. Since we are concerned with such a diverse range of mixing configurations, we should also develop a more systematic way to assign all mixing parameters directly from the CFD simulation. Another disadvantage is step 3, in which the flowfield is subdivided into zones based on streamlines. This procedure becomes less certain for progressively more complex flow fields.

L. S. Pedersen, P. Glarborg, K. Dam-Johansen, P. W. Hepburn, and G. Hesselmann, “A chemical engineering model for predicting NO emissions and burnout from pulverized coal flames," Combust. Sci. and Tech., 132: 251-314 (1998).

\subsection{Temperature/Concentration Mapping (TCMP)}

This approach was developed at ENEL, an Italian utility company. It proceeds through the following steps:

(1) Determine RTDs from the CFD simulations with particle tracking.

(2) Evaluate the temperature and S. R. value for each cell in the CFD solution. Plot all points as temperature versus S. R. Identify all correlations with physical significance. For example, the parabolic relation between $\mathrm{T}$ and $\mathrm{S}$. R. with a maximum near $\mathrm{S}$. R. $=1$ for adiabatic flame temperature indicates the volumes associated with primary flame zones.

(3) Group all cells into homogeneous zones based on the T/S. R. correlations. Average the temperature and S. R. values for each 
zone, and determine zone volume by summing the volume of its cells. Determine mass fluxes into and out of the zone directly from the CFD flowfield.

Associate a reactor with each zone on the basis of the orientation of velocity vectors across the zone. CSTRs are appropriate when the orientation of velocity vectors is random; PFRs are best when the velocity vectors are near-axial.

Determine an RTD for the equivalent network, and tune network parameters to match the CFD-based RTD.

Simulate the chemistry.

The main advantage to this approach is that $\mathrm{S}$. R. fields from the CFD simulations are directly used to specify mixing conditions in the equivalent network. Unfortunately, the S. R. values are only matched as average values over relatively large regions of the combustor. This scheme (as implemented at ENEL) does not include the distributed air addition manifolds used in ZwDM. I think this is a major deficiency, but one which can be rectified in our work. Another disadvantage is that the grouping of cells according to their T/S. R. characteristics seems even more arbitrary than the zoning in ZwDM.

D. Benedetto, S. Pasini, M. Falcitelli, C. LaMarca, and L. Tognotti, "NOx emission prediction from 3-D complete modeling to reactor network analysis," Combust. Sci. and Tech., 153: 279-294 (2000).

\subsection{Mixing Effectiveness Parameters (MXPR)}

Fiveland and coworkers (while at B\&W) formally evaluated parameters from CFD solutions whose values indicated the extents of mixedness among streams in coalfired boilers. They were called, among other things, "mixing effectiveness parameters." The intent was to quantitatively describe the regions of furnaces whose behavior was critically determined by mixing among dissimilar streams; e. g., air injected through OFA ports or reburning fuel injection operations. The group did not ever try to use the parameters to infer anything about equivalent reactor networks, as we are doing in this project.

The parameters were defined by analogy to the mixture fraction variables that are routinely used to characterize the mixing of fuel and air in turbulent diffusion flames. For example, the parameter for OFA stream mixing was defined as the local temperature assigned from an adiabatic enthalpy balance, because the bulk furnace stream and the OFA were at completely different temperatures at their respective inlet positions. The key requirement is that the behavior of the mixture fraction and other so-called "conserved scalars" have local values which are determined solely by mixing mechanisms, and not by reaction mechanisms or other transport processes. In other words, conserved scalars can advect and diffuse throughout the furnace volume, but they are not generated or destroyed. 
I think these parameters are relevant to our activities because they explicitly demonstrate how mixing rates can be quantitatively specified from fields of mixture fractions or the other conserved scalars. There really is no need to adjust mixing parameters in any ad hoc manner, because the fields of conserved scalars throughout a CFD furnace simulation indicate the proportions of inlet streams that have mixed up to a particular position. Obviously it becomes more difficult to deconvolute the mixing process at positions that are further away from the fuel and air injection ports. But mixing also matters most near the injection ports, where the gradients are steepest.

W. A. Fiveland, C. E. Latham, A. D. LaRue, "Combustion system optimization by advanced modeling technology," In Combustion Modeling and Burner Replacement Strategies, Vol. 10, R. V. Nayak and N. A. Mousa (Eds.), FACT Div., ASME, 1990 Int. Joint Power Generation Conf., Oct. 21-25, 1990, Boston, MA, ASME, 1990, NY, NY, pp. 15-22.

\subsection{NEA'S PROPOSED APPROACH}

\subsection{Scope and Objectives}

Our aim is to translate a CFD simulation into an equivalent network of idealized reactors that imposes the same reaction conditions as the furnace components. The network formulation should explicitly recognize the associations among air entrainment rates, reaction time distributions, temperature fields, and local S. R. values that govern $\mathrm{NO}_{\mathrm{X}}$ production, in particular, and most other important aspects of the combustion behavior. These associations determine the structure of the flame, and structure cannot possibly be ignored in any modern attempt to forecast $\mathrm{NO}_{\mathrm{X}}$ and $\mathrm{CO}$ emissions and burnout. Whereas this emphasis seems like a truism to any combustion engineer, it is foreign to the chemical engineering community that traditionally develops equivalent networks of reactors. The main distinction is that RTDs are traditionally based on the entire reactor volume, whereas we need to know RTDs for each distinctive zone of the flame, because the rates of combustion and emissions production vary widely among zones, depending on local temperatures, S. R. values, and residence times.

We also believe that it will be unnecessary (and perhaps futile) to delineate flame zones in terms of uniform, average values of S. R. and temperature. Since mixing is a steady flow process, we will use the CFD simulations to characterize the extent that a particular air stream has mixed with a fuel or product gas stream at a specific position in the flow field. By application of Glarborg's distributed air injection mechanism, we will actually be inferring the local air addition rates along the primary flow direction across each zone in the flame. CSTRs will be used for zones that have no primary flow direction. Then profiles of temperature and S. R. will be assigned across the flame zones, rather than any constant values. The profiles will only be specified to be uniform throughout any cross section of the flow that it perpendicular to the flow direction, as in a PFR. 
Flame zones will be identified directly from the field of a conserved scalar variable in the CFD simulation. As explained below in more detail, values of the best choice of variables for this application directly indicate whether fuel is mixing with air or vice versa at each position in the flow field. So the variable field reveals the flame zones in terms of volumes that have the conserved scalar variable within a restricted range of values. After the regions are identified, we then specify their temperature profiles, air addition rates, and RTDs from the CFD simulations.

Once the operating conditions have been specified for each flame zone, traditional chemical engineering methods can be used to identify the equivalent network of reactors for each flame zone. CSTR tanks-in-series will be used throughout for the sake of computational expedience.

Hence, NEA's approach moves through the following six stages:

(1) Evaluate in the CFD simulation a conserved scalar variable whose value delineates distinctive flame zones. Assign the volumes of all flame regions and the associated 1-D temperature profiles from the CFD simulations.

(2) Determine air addition rates directly from the field of the conserved scalar.

(3) Use particle tracking through each flame zone to assign "regional" RTDs.

(4) Assign mass flows of gas and particles into all zones.

(5) Use CSTR tanks-in-series to represent each regional RTD.

(6) Simulate the chemistry.

It appears that this method of defining the equivalent network of reactors will have no adjustable parameters whatsoever. The number of CSTRs in series for each zone will come directly from the regional RTD, which is specified from the CFD simulation. Similarly, the volume, temperature, and flowrates of air and fuel into each CSTR come from the CFD simulation. Since the actual flow patterns in the furnace are being approximated by a network of 1-D and well-mixed regions, it may be necessary to tunein the network to match the RTD of the entire furnace, but this should only be a minor adjustment.

We next consider each step in the method in greater detail.

\subsection{Delineating Flame Zones (Step 1)}

To proceed further with more detail, it will be useful to focus on a single burner with a single external air stream. Consider one primary stream of coal in air plus one swirled secondary air stream. Assume that swirl numbers are too low to sustain any IRZ, like SRI's tangential-like flame.

The best choice for the conserved scalar variable will be the following mixture fraction variable: 


$$
f=\frac{Z_{C}(x, y, z, t)-Z_{C, P}}{Z_{C, S}-Z_{C, P}}
$$

where $Z_{C}(x, y, z, t)$ is the local mass fraction of carbon, regardless of phase, and the subscripts $\mathrm{P}$ and $\mathrm{S}$ denote primary and secondary streams into a burner, respectively. If there is no carbonaceous material in the secondary air stream, then $Z_{C, S}$ is zero and

$$
f=1-\frac{Z_{C}(x, y, z, t)}{Z_{C, P}}
$$

Note that $0 \leq f \leq 1-Z_{C, S} / Z_{C, P}$ represents the a continuous domain of fuel concentrations from the primary stream through the secondary air stream, including all possible mixture concentrations. A value of special significance is

$f_{M}=1-\frac{Z_{C, M}}{Z_{C, P}}$ where $\quad Z_{C, M}=\frac{\dot{m}_{P} Z_{C, P}+\dot{m}_{S} Z_{C, S}}{\dot{m}_{P}+\dot{m}_{S}}$

Values denoted by subscript $\mathrm{M}$ represent the carbon fraction in the complete mixture of the primary and secondary streams. They can be used to delineate zones of similar S. R. values and, more importantly, to indicate whether a particular region in the flow has air mixing with fuel or vice versa.

In the single swirled burner, the flows at the inlet are segregated with all fuel on the centerline. Consequently, in the flame core, $0 \leq f \leq f_{M}$, and values of $f$ can only indicate that air is mixing into the primary stream. In the mixing layer, $f_{M} \leq f \leq 1-Z_{C, S}$ $/ Z_{C, P}$, and values of $f$ can only indicate that fuel or products are mixing into the secondary air stream. The same restricted domain on $f$ also applies to an ERZ, although we should expect values close to unity in the mixing layer and values much closer to $f_{M}$ in an ERZ.

Radial profiles of $f$ are sketched for four axial positions along the flame axis in Fig. 1. These values are based on the time-mean compositions across the flame. Near the quarl (position 1), the flame core composition is essentially unperturbed from the primary stream composition, so there is a very steep gradient in $f$ across the mixing layer, where the magnitude increases from near-zero to near-unity. There is then a similarly steep gradient into the ERZ, over which the magnitude of $f$ falls to approximately $f_{M}$. For progressively greater distances from the quarl, the values of $f$ in the flame core gradually increase due to air entrainment, while the maximum values in the mixing layer diminish due to the addition of products from the ERZ and flame core. Values in the ERZ remain fairly constant along the entire flame length. 
The value of $f_{M}$ in Fig. 1 is approximately three-fourths of the secondary air value, which would apply when the mass flow of coal is 10 to $15 \%$ of the total air flow and the secondary air flow is four times the primary air flow. The nominal value of $f$ in an ERZ

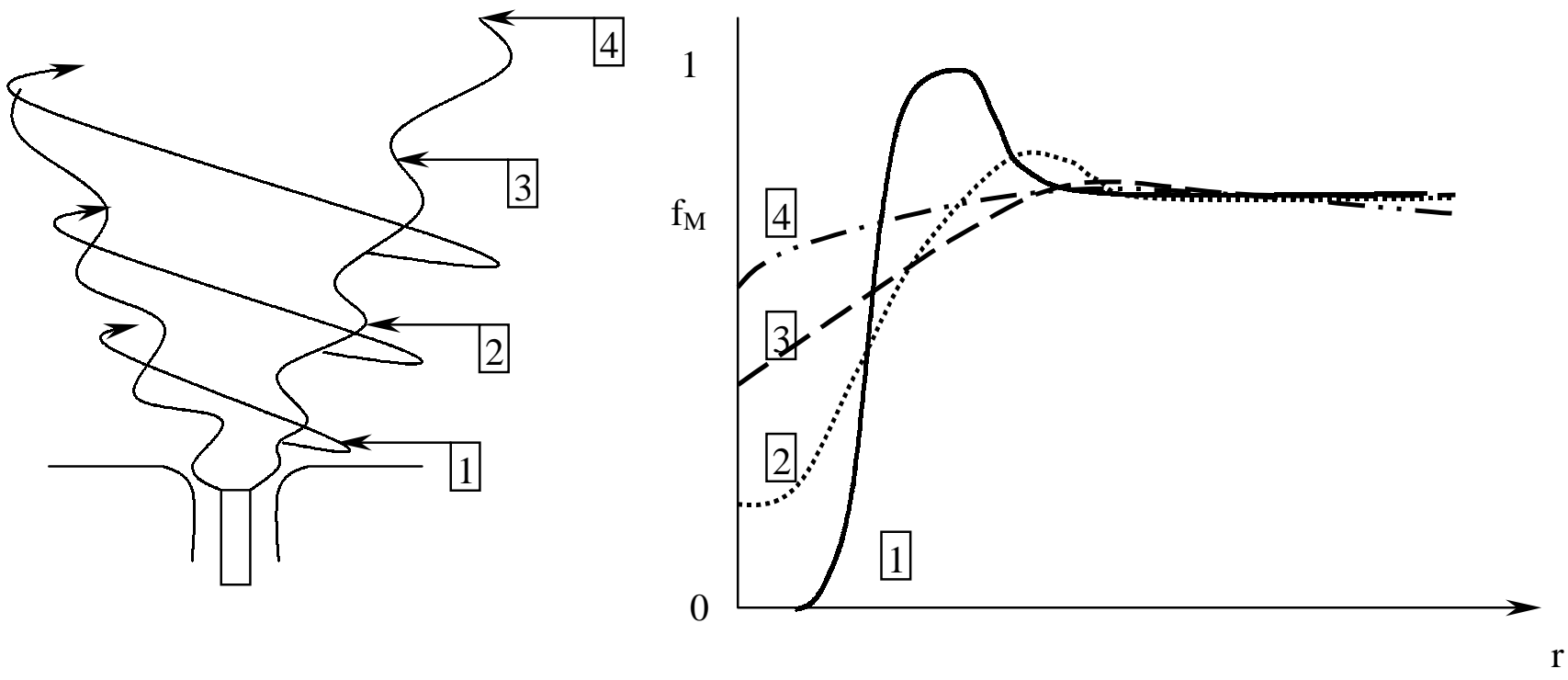

Figure 1. (Left) Swirled flame with four axial positions indicated; (Right) Radial profiles of $f$ for the same four axial positions.

will not necessarily equal $f_{M}$, because particle loadings will be much higher in the flame exhaust than in the ERZ. If the extent of burnout at the axial position where the jet expansion zone ends is low, then the value of $f$ in the ERZ will be significantly greater than $f_{M}$, and the value for the exhaust leaving the flame brush will be correspondingly lower near the centerline of the flow.

Most important, the $f$-profiles delineate distinctive flame zones with regard to the process chemistry. The flame core can be defined explicitly as the region away from the centerline where $0 \leq f \leq f_{M}$. The cross section of this volume grows with distance away from the quarl, due to air addition and heat release. Once the volume has been identified, it is a simple matter to assign area-averaged temperatures and f-values, according to

$$
\langle f(z)\rangle=\frac{1}{r_{P}(z)} \int_{0}^{r_{P}(z)} r f d r
$$

where $r_{P}(z)$ is the radial position where $f=f_{M}$. The volume of the flame zone can also be determined by integration.

The same procedure will be used to determine the characteristics of the mixing layer by focusing on the region where $f_{M} \leq f \leq 1-Z_{C, S} / Z_{C, P}$. Although the mixing layer 
cannot be distinguished from the ERZ on the basis of $f$-values, the extent of the ERZ will be apparent in the locus of zero axial velocity in the CFD simulation.

\subsection{Assigning Air Addition Rates (Step 2)}

The procedure to identify the flame zones delivers profiles of temperature and $f$ along the flow direction through each zone. This information can next be used to assign air addition rates, based on the assumption that the value of $f$ at any point represents a binary mixing process in one dimension. In other words, the carbon mass fraction at any point represents a mixture of the primary and secondary streams, according to:

$$
Z_{C}(z)=\frac{\dot{m}_{P} Z_{C, P}-\dot{m}_{E}(z) Z_{C, S}}{\dot{m}_{P}-\dot{m}_{E}(z)}
$$

This relation can be rearranged into an explicit definition for the flowrate of air added to the primary stream, $m_{E}(z)$, which is

$$
\dot{m}_{E}(z)=\frac{\dot{m}_{P}\langle f(z)\rangle}{1-\langle f(z)\rangle}
$$

This expression should be regarded as approximate because we have admitted the possibility that fuel components mix with the secondary air stream. Any fuel removed from the primary stream should also be accounted for in eq. 3.5. In actuality, eq. 3.6 is an approximation for a system of algebraic equations that must be solved simultaneously.

\subsection{Finalizing An Equivalent Network (Steps 3-5)}

Only the regional RTD and mass flows into each flame zone remain to be specified. Since the volume of each flame zone has already been specified, the regional RTDs can be determined by particle tracking. Coal particles, rather than fluid particles, should be tracked because the zones were defined from the carbon fraction field and all carbon enters the furnace as coal particles.

The RTD automatically specifies the number of CSTRs in series that should be used to represent each zone in the equivalent network. As developed in the standard texts on reaction engineering, the variance of the RTD, $\sigma_{i}$, determines the number of CSTRs as follows:

$$
n=\frac{1}{\sigma_{i}^{2}}
$$


This simple result pertains to a series of tanks of the same size with a single feedstream into each tank. It must be subjected to further analysis to account for the addition of air at the inlets to each CSTR in our modeling and variable CSTR volumes. Whereas these complications will probably complicate the relation between the tank number and the variance, we can still expect the RTD to fully specify the equivalent network for each flame zone in the model. The analysis is also robust, in the sense that it will represent RTDs of exponential form $(n=1)$, gamma distributions (intermediate $n$ ), gaussian distributions (large $\mathrm{n}$ ), and delta functions (very large $\mathrm{n}$ ).

The same tracking procedure used to determine the regional RTDs also specifies the fluxes of particles entering and leaving each flame zone. Particles will actually enter and leave each zone on and off the single flow axis in the idealized network, so the fluxes should be resolved into their component directions. The off-axis components can either be added (or subtracted) to the inlets to the CSTR in the series for the particular axial position under consideration, or lumped into the main inlet and outlet for the series. Since the volume and location of each flame zone are specified, the fluxes of gas throughout each zone can be assigned directly from the CFD simulation.

\subsection{Simulate the Chemistry (Step 6)}

Regardless how the equivalent network is specified, the final step of simulating the chemistry can be (and has already been) done with CHEMKIN III and PC Coal Lab.

\section{Next Steps}

It is important at this preliminary stage in the project that we think hard to identify pitfalls in the previously reported and proposed approaches to specifying an equivalent network from a CFD simulation. I am excited about the potential of the carbon mass fraction to significantly improve the specification. 